\title{
The Peritraumatic Distress Inventory: A Proposed Measure of PTSD Criterion A2
}

\author{
Alain Brunet, Ph.D. \\ Daniel S. Weiss, Ph.D. \\ Thomas J. Metzler, M.A. \\ Suzanne R. Best, Ph.D. \\ Thomas C. Neylan, M.D. \\ Cynthia Rogers, B.A. \\ Jeffrey Fagan, Ph.D. \\ Charles R. Marmar, M.D.
}

\begin{abstract}
Objective: Meeting criterion A2 for the diagnosis of posttraumatic stress disorder (PTSD) in DSM-IV requires that an individual have high levels of distress during or after the traumatic event. Because of the paucity of valid and reliable instruments for assessing such responses, the authors developed a 13-item self-report measure, the Peritraumatic Distress Inventory, to obtain a quantitative measure of the level of distress experienced during and immediately after a traumatic event.
\end{abstract}

Method: The cross-sectional study group comprised 702 police officers and 301 matched nonpolice comparison subjects varying in ethnicity and gender who were exposed to a wide range of critical incidents.
Results: The Peritraumatic Distress Inventory was found to be internally consistent, with good test-retest reliability and good convergent and divergent validity. Even after controlling for peritraumatic dissociation and for general psychopathology, the authors found that Peritraumatic Distress Inventory scores correlated with two measures of posttraumatic stress symptoms.

Conclusions: The Peritraumatic Distress Inventory holds promise as a measure of PTSD criterion A2. Future studies should prospectively examine the ability of the Peritraumatic Distress Inventory to predict PTSD and its associated biological and cognitive correlates in other traumaexposed groups.

(Am J Psychiatry 2001; 158:1480-1485)
? he diagnostic criteria for posttraumatic stress disorder (PTSD) in DSM-III specified that events were traumatic if they were outside the realm of usual human experience and would evoke significant distress in the vast majority of people. The finding that a traumatic event will occur at some time in the lives of more than half of the adults in the United States (1) necessitated revision of this specification. In DSM-IV the exposure criterion was modified into two components. Criterion Al specifies that the event must represent a serious threat to the self or to others; criterion A2 requires that the initial response to the event involve fear, helplessness, or horror. This change fundamentally reconceptualized trauma exposure, explicitly acknowledging the wide individual differences in immediate response.

There are several reasons to study responses occurring at the time of a trauma and immediately after, a time frame that has come to be called "peritraumatic" (2). Selfreported peritraumatic responses might explain additional variability in PTSD symptoms over and above the objective trauma characteristic, a view supported by a meta-analysis (3) that found peritraumatic dissociation to be a better predictor of PTSD than objective trauma characteristics. Given that acute dissociative responses occur in the context of elevated distress (4) and that not everyone who experiences high levels of distress during trauma has a dissociative response, peritraumatic distress may have predictive value over and above peritraumatic dissociation. Indeed, it has been proposed that peritraumatic anxious arousal enhances trauma-related memory (5) and sensitizes the neurobiological systems implicated in the pathogenesis of PTSD (6). This hypothesis cannot be fully investigated without valid and reliable instruments for assessing peritraumatic emotional distress.

With the intent of creating an inventory of immediate responses to trauma, we reviewed the literature and found studies reporting heightened emotional distress and bodily arousal as concomitants of trauma exposure. Examples included feelings of personal life threat $(7)$, fear $(8,9)$, feelings of helplessness $(9,10)$, horror $(9)$, guilt and shame $(9,11)$, anger $(9,12)$, loss of bowel and bladder control $(11,13)$, and shaking, trembling, and increased heart rate $(8,14-16)$.

In this article we present the psychometric properties of the Peritraumatic Distress Inventory as developed in a study group of police officers; we also examine both reliability and validity of the instrument. We show that peritraumatic distress scores are positively associated with two measures of PTSD symptoms, even after partialling out variance accounted for by general psychopathology or by peritraumatic dissociation. Finally, we extend those results to a study group of civilians.

\section{Method}

\section{Participants and Procedure}

Police officers ( $\mathrm{N}=747)$ were recruited from the police departments of New York City and Oakland and San Jose, Calif., in a study whose goal was to examine levels of PTSD symptoms as 
BRUNET, WEISS, METZLER, ET AL.

TABLE 1. Characteristics of Police Officers and Comparison Subjects Who Completed the Peritraumatic Distress Inventory

\begin{tabular}{|c|c|c|c|c|c|c|c|}
\hline \multirow[b]{2}{*}{ Characteristic } & \multicolumn{2}{|c|}{ Police Officers ( $N=702)$} & \multicolumn{2}{|c|}{ Comparison Subjects $(\mathrm{N}=301)$} & \multicolumn{3}{|c|}{ Analysis } \\
\hline & $\mathrm{N}$ & $\%$ & $\mathrm{~N}$ & $\%$ & $\chi^{2}$ & $\mathrm{df}$ & $r_{\mathrm{s}}$ \\
\hline Gender & & & & & $39.87^{* *}$ & 1 & $\overline{0.20}$ \\
\hline Male & 551 & 78.5 & 179 & 59.5 & & & \\
\hline Female & 145 & 20.7 & 120 & 39.9 & & & \\
\hline Undisclosed & 6 & 0.9 & 2 & 0.7 & & & \\
\hline Education & & & & & $41.35^{\star *}$ & 2 & 0.20 \\
\hline Up to high school diploma & 226 & 32.2 & 94 & 31.2 & & & \\
\hline Associate or bachelor's degree & 452 & 64.4 & 168 & 55.8 & & & \\
\hline Graduate school & 24 & 3.4 & 39 & 13.0 & & & \\
\hline Household income & & & & & $96.98^{* *}$ & 3 & -0.21 \\
\hline Up to $\$ 50,000$ & 82 & 11.7 & 113 & 37.5 & & & \\
\hline$\$ 50,001-\$ 70,000$ & 256 & 36.5 & 76 & 25.2 & & & \\
\hline$\$ 70,001-\$ 90,000$ & 173 & 24.6 & 43 & 14.3 & & & \\
\hline$\geq \$ 90,001$ & 191 & 27.2 & 69 & 22.9 & & & \\
\hline Marital status & & & & & $9.20^{*}$ & 5 & 0.06 \\
\hline Married & 422 & 60.1 & 157 & 52.2 & & & \\
\hline Living together & 55 & 7.8 & 25 & 8.3 & & & \\
\hline Steady relationship & 48 & 6.8 & 20 & 6.6 & & & \\
\hline Divorced & 69 & 9.8 & 29 & 9.6 & & & \\
\hline Widowed & 3 & 0.4 & 0 & 0.0 & & & \\
\hline Single & 97 & 13.8 & 70 & 23.3 & & & \\
\hline Undisclosed & 8 & 1.1 & 0 & 0.0 & & & \\
\hline Ethnicity & & & & & $47.25^{* *}$ & 3 & -0.18 \\
\hline Caucasian & 312 & 44.4 & 198 & 65.8 & & & \\
\hline African American & 154 & 21.9 & 37 & 12.3 & & & \\
\hline Hispanic & 175 & 24.9 & 35 & 11.6 & & & \\
\hline Other/multiple & 51 & 7.3 & 24 & 8.0 & & & \\
\hline Undisclosed & 10 & 1.4 & 7 & 2.3 & & & \\
\hline
\end{tabular}

${ }^{*} \mathrm{p}<0.05 . \quad * * \mathrm{p}<0.001$.

well as risk and resilience factors for PTSD. Potential participants were selected from departmental personnel rosters with a proportionally higher pool of minority and female officers. In all other respects selection was random. To assemble a comparison group, we asked the officers to nominate nonpolice peers who were matched in age and gender. These men and women were then asked to participate. The groups are best described as convenience study groups.

The mean age of the 702 police officers who reported a valid critical incident as their index event (explained in the section on critical incident exposure) was 36.98 years ( $\mathrm{SD}=6.79$, range $=21-$ $62)$; the mean age of the 301 comparison subjects who reported a valid critical incident was $36.68(\mathrm{SD}=8.15$, range $=20-69)(\mathrm{t}=0.60$, $\mathrm{df}=1,001, \mathrm{p}>0.05$ ). Table 1 presents the other demographic characteristics of these police officers and comparison subjects; the groups differed on a number of variables.

After the procedure was fully explained, written consent was obtained from all participants. Subjects were given a self-report questionnaire, a return envelope, and an offer of $\$ 100$ reimbursement.

\section{Instruments}

Peritraumatic Distress Inventory. The instruction for the Peritraumatic Distress Inventory is to rate the extent to which each item was experienced "during the critical incident you selected and immediately after." The response format is a Likert scale that ranges from 0 to 4 ( $0=$ not at all, $1=$ slightly, $2=$ somewhat, $3=$ very, and $4=$ extremely true). The Peritraumatic Distress Inventory items are provided in Table 2 . The total score is obtained by determining the mean response across all 13 items.

Critical incident exposure. To assess critical incident exposure, we used the Critical Incident History Questionnaire (17) for police officers and the Trauma History Questionnaire (18) for comparison subjects. After completing these measures, participants were asked to select one event that had up to the present been "the most troublesome, disturbing, or distressing." This index event was used for completing other incident-specific questionnaires.
Index events were classified by a research assistant using a coding scheme derived in part from the Evaluation of Lifetime Stressors Questionnaire and Interview (19). Severity of critical incident exposure was classified into one of four categories: experiencing, witnessing, hearing of a significant other having experienced a critical incident, or absence of a critical incident involving a threat to the physical integrity of self or other. Event type was classified in one of the following categories: accident, natural disaster, physical assault, sexual assault, illness/injury or death, combat, harassment/threats, or other critical incident. Of all the index events, $20 \%$ were independently rated by a psychologist with expertise in PTSD; kappas of 0.71 and 0.79 were achieved for event type and severity, indicating substantial interrater agreement between the psychologist and the research assistant.

Trauma-related measures. In relation to the index event, the participants completed three measures: 1) the Peritraumatic Dissociative Experiences Questionnaire (2), which assesses dissociative experiences at the time of a critical incident; 2) the Impact of Event Scale-Revised (20), which measures PTSD symptoms of intrusion, avoidance, and arousal within the last 7 days; and 3) the civilian version of the Mississippi Scale for Combat-Related PTSD (21), which provides a cumulative measure of PTSD and associated symptoms since the occurrence of the index event. Both the Impact of Event Scale-Revised and the Civilian Mississippi Scale provide dimensional assessments of PTSD symptom levels rather than categorical determinations of PTSD diagnosis.

Other measures. The SCL-90-R (22) was used to examine current general psychopathology symptoms. Current level of perceived social support was assessed with the Sources of Support measure (23). The Marlowe-Crowne Scale form C (24) was used to assess social desirability. The 12-item Short-Form Health Survey (25) was used to assess current physical health.

\section{Statistical Analyses}

All analyses were two-tailed, with an alpha of 0.05. We controlled for family-wise error rate by using the false discovery rate 
TABLE 2. Endorsement of Items on the Peritraumatic Distress Inventory by Police Officers and Comparison Subjects Who Completed Measures Assessing Reactions to Traumatic Events ${ }^{\text {a }}$

\begin{tabular}{|c|c|c|c|c|c|c|c|c|c|c|}
\hline \multirow[b]{3}{*}{ Item Description } & \multicolumn{5}{|c|}{ Police Officers $(\mathrm{N}=702)$} & \multicolumn{5}{|c|}{ Comparison Subjects $(\mathrm{N}=301)$} \\
\hline & \multicolumn{2}{|c|}{$\begin{array}{l}\text { Endorsed } \\
\text { Item }\end{array}$} & \multicolumn{2}{|c|}{ Score } & \multirow{2}{*}{$\begin{array}{c}\text { Correlation } \\
\begin{array}{c}\text { Between Item Score } \\
\text { and Total Score }\end{array} \\
r_{\mathrm{s}}\end{array}$} & \multicolumn{2}{|c|}{$\begin{array}{l}\text { Endorsed } \\
\text { Item }\end{array}$} & \multicolumn{2}{|c|}{ Score } & \multirow{2}{*}{$\begin{array}{c}\text { Correlation } \\
\begin{array}{c}\text { Between Item Score } \\
\text { and Total Score }\end{array} \\
r_{\mathrm{s}}\end{array}$} \\
\hline & $\mathrm{N}$ & $\%$ & Mean & SD & & $\mathrm{N}$ & $\%$ & Mean & SD & \\
\hline I felt helpless to do more & 492 & 70.1 & 1.7 & 1.4 & 0.50 & 254 & 84.4 & 2.2 & 1.4 & 0.40 \\
\hline I felt sadness and grief & 529 & 75.4 & 2.1 & 1.5 & 0.30 & 266 & 88.4 & 2.8 & 1.4 & 0.31 \\
\hline & & & & & & & & & & \\
\hline $\begin{array}{l}\text { more } \\
\text { I felt afraid for my safety }\end{array}$ & $\begin{array}{l}544 \\
366\end{array}$ & $\begin{array}{l}77.5 \\
52.1\end{array}$ & $\begin{array}{l}2.1 \\
1.4\end{array}$ & $\begin{array}{l}1.5 \\
1.6\end{array}$ & $\begin{array}{l}0.52 \\
0.22\end{array}$ & $\begin{array}{l}272 \\
156\end{array}$ & $\begin{array}{l}90.4 \\
51.8^{b}\end{array}$ & $\begin{array}{l}2.7 \\
1.4\end{array}$ & $\begin{array}{l}1.3 \\
1.6^{b}\end{array}$ & $\begin{array}{l}0.43 \\
0.36\end{array}$ \\
\hline I felt guilt that more was not done & 314 & 44.7 & 1.0 & 1.3 & 0.47 & 174 & 57.8 & 1.3 & 1.4 & 0.38 \\
\hline I felt ashamed of my emotional reactions & 174 & 24.8 & 0.4 & 0.9 & 0.41 & 123 & 40.9 & 0.9 & 1.3 & 0.35 \\
\hline I felt worried about the safety of others & 437 & 62.3 & 1.7 & 1.5 & 0.20 & 137 & 45.5 & 1.1 & 1.5 & 0.18 \\
\hline $\begin{array}{l}\text { I had the feeling I was about to lose } \\
\text { control of my emotions }\end{array}$ & 246 & 35.0 & 0.7 & 1.1 & 0.51 & 209 & 69.4 & 1.6 & 1.4 & 0.49 \\
\hline $\begin{array}{l}\text { I had difficulty controlling my bowel and } \\
\text { bladder }\end{array}$ & 23 & 3.3 & 0.1 & 0.4 & 0.21 & 21 & 7.0 & 0.1 & $0.5^{\mathrm{b}}$ & 0.22 \\
\hline $\begin{array}{l}\text { I was horrified by what happened } \\
\text { I had physical reactions like sweating, }\end{array}$ & 430 & 61.3 & 1.5 & 1.5 & 0.40 & 183 & $60.8^{\mathrm{b}}$ & 1.6 & $1.5^{\mathrm{b}}$ & 0.45 \\
\hline shaking, and pounding heart & 444 & 63.2 & 1.5 & 1.4 & 0.51 & 220 & 73.1 & 2.0 & 1.5 & 0.53 \\
\hline I felt I might pass out & 77 & 11.0 & 0.2 & 0.8 & 0.33 & 94 & 31.2 & 0.7 & 1.2 & 0.42 \\
\hline I thought I might die & 203 & 28.9 & 0.7 & 1.3 & 0.27 & 105 & $34.9^{b}$ & 0.9 & 1.5 & 0.44 \\
\hline
\end{tabular}

procedure for each family of tests (26). Twenty-five percent of the participants had missing data, representing $0.4 \%$ of all data points. No significant relationship was found between the patterns of missing data and Peritraumatic Distress Inventory results. Missing values on all interval or ratio scales except the Peritraumatic Distress Inventory and the critical incidents were calculated by using the expectation maximization method (27). An a priori power analysis indicated greater than $80 \%$ power to detect correlations of 0.11 in officers and 0.18 in comparison subjects.

\section{Results}

\section{Trauma Exposure and Index Events}

Exposure severity for the officers' index events was as follows: $322(45.9 \%)$ personally experienced a critical incident, 308 (43.9\%) were witness to an incident, and 72 (10.3\%) heard of the exposure of a close friend or relative to a critical incident. The incidents included accidents $(\mathrm{N}=$ $8,1.1 \%)$, natural disasters $(\mathrm{N}=4,0.6 \%)$, physical assaults $(\mathrm{N}=157,22.4 \%)$, sexual assaults $(\mathrm{N}=17,2.4 \%)$, illnesses/injuries or deaths $(\mathrm{N}=449,64.0 \%)$, harassment/threats $(\mathrm{N}=$ $44,6.3 \%)$, and other critical incidents ( $\mathrm{N}=16,2.3 \%)$.

Exposure severity for the index event in comparison subjects included personally experiencing a critical incident $(\mathrm{N}=182,60.5 \%)$, witnessing a critical incident $(\mathrm{N}=49$, $16.3 \%$ ), and hearing of the exposure of a close friend or relative to a critical incident $(\mathrm{N}=70,23.3 \%)$. The index events included accidents $(\mathrm{N}=11,3.7 \%)$, disasters $(\mathrm{N}=8,2.7 \%)$, physical assaults $(\mathrm{N}=52,17.3 \%)$, and sexual assaults $(\mathrm{N}=15$, $5.0 \%)$, illnesses/injuries or deaths $(\mathrm{N}=156,51.8 \%)$, combat $(\mathrm{N}=4,1.3 \%)$, harassment/threats $(\mathrm{N}=38,12.6 \%)$, and other critical incidents $(\mathrm{N}=17,5.6 \%)$. Most index events were not of recent origin: the mean time since the incident for officers was 6.64 years ( $\mathrm{SD}=5.16)$; for the comparison subjects it was 8.83 years $(\mathrm{SD}=6.50)$. The groups did not differ in terms of social desirability $(\mathrm{t}=0.64, \mathrm{df}=1,001, \mathrm{p}>0.05)$.

\section{Peritraumatic Distress Inventory Psychometrics}

The Peritraumatic Distress Inventory is derived from an earlier scale, the 23-item Peritraumatic Emotional Distress Scale (28). Items were revised by a panel of six researchers and clinicians working in the field of PTSD (A.B., D.S.W., S.R.B., T.C.N., C.R.M.) and violence (J.F.). Nine items were retained and three were reformulated. Eleven items were dropped on the basis of a consensus that they did not apply to a wide array of critical incidents. Nine new items were added on the basis of a literature review and the clinical experience of the panel members, for a total of 21 . In a preliminary report, we examined the factor analytic structure of this pool of 21 items, which yielded three factors (29). Because one of these factors included a method confound and several of its items did not occur strictly within a peritraumatic time frame, that factor was dropped, along with its items.

We performed a new principal factor analysis using the remaining set of 13 items. Squared multiple correlations were used as initial communality estimates. Estimates were iterated. An oblique promax rotation was performed on the factors with an eigenvalue greater than 1 . The first factor (negative emotions) had seven items, and the second (perceived life threat and bodily arousal) had six. Factors 1 and 2 had eigenvalues of 3.00 and 1.98, explaining, respectively, $23 \%$ and $15 \%$ of the total variance (38\%). Factors 1 and 2 explained $60 \%$ and $40 \%$ of the common variance, respectively, and were modestly correlated $(r=0.20)$. Use of a rotated orthogonal solution did not change the number of factors, their item content, and item loadings. 
Confirmatory factor analysis was used to replicate the factor solution in the comparison group of non-police-officers; the major goodness-of-fit indexes were in the adequate-to-good-fit range.

As shown in Table 2, the most frequently endorsed items in both groups were feeling frustrated or angry, feeling sadness and grief, and feeling helpless. The least endorsed items in both groups were losing control of one's bowel and bladder and passing out. Most officers ( $\mathrm{N}=639,91 \%)$ and comparison subjects $(\mathrm{N}=277,92 \%)$ endorsed one or more of the three items included in DSM-IV criterion A2 (fear, helplessness, or horror). Overall, comparison subjects more frequently endorsed Peritraumatic Distress Inventory items, and their mean level of endorsement was higher than that of the officers. One exception was that the police officers more often reported worrying about the safety of others.

We next examined the distribution of the responses and temporal stability of Peritraumatic Distress Inventory scores. In both groups, most item distributions were positively skewed. However, the distribution of total Peritraumatic Distress Inventory scores was symmetrical in both study groups. The standardized coefficient alpha for the total Peritraumatic Distress Inventory score was 0.75 in officers and 0.76 in comparison subjects. A subgroup of officers $(\mathrm{N}=71)$ was retested on the Peritraumatic Distress Inventory an average of 391 days $(S D=130$, range $=80-585)$ after initial measure completion. The test-retest correlation coefficient was 0.74 , indicating very good temporal stability. A modest decrease in mean score across time was observed $(\mathrm{t}=2.76, \mathrm{df}=70, \mathrm{p}<0.01 ; \mathrm{d}=0.25)$.

\section{Sociodemographic Differences on the Peritraumatic Distress Inventory}

To test for the effects of age, gender, ethnicity (Caucasian or other) and group (officer or comparison subject), we conducted a two-by-two-by-two analysis of covariance with age as a covariate among the participants with complete sociodemographic data $(\mathrm{N}=984)$. We could not test the comparison of African American and Hispanic subjects because of small cell sizes for the comparison group. The overall model was significant $(\mathrm{F}=9.11, \mathrm{df}=8,984$, $\mathrm{p}<0.001)$. The age covariate was not significant $(\mathrm{F}=0.16$, $\mathrm{df}=1,984, \mathrm{p}>0.05)$. No main effect was found for ethnicity $(\mathrm{F}=0.11, \mathrm{df}=1,984, \mathrm{p}>0.05)$. Main effects were found for gender $(\mathrm{F}=11.67, \mathrm{df}=1,984, \mathrm{p}<0.001)$ and for group $(\mathrm{F}=$ 46.41, $\mathrm{df}=1,984, \mathrm{p}<0.001)$. Women had higher scores on the Peritraumatic Distress Inventory than men (mean= $1.44, \mathrm{SD}=0.74$, compared with mean $=1.26, \mathrm{SD}=0.64)(\mathrm{d}=$ 0.27 ), and so did the comparison subjects (mean $=1.52$, $\mathrm{SD}=0.69$ ) compared with the police officers (mean $=1.17$, $\mathrm{SD}=0.64)(\mathrm{d}=0.53)$. The only significant interaction term was the gender-by-group term $(\mathrm{F}=5.78, \mathrm{df}=1,984, \mathrm{p}<0.05)$. There was no difference between groups among men, but female officers scored lower (mean $=1.37, \mathrm{SD}=0.65)$ than their civilian counterparts (mean $=1.67, \mathrm{SD}=0.76)(\mathrm{d}=0.43)$.

\section{Convergent and Divergent Validity of the Peritraumatic Distress Inventory}

Among police officers, the Peritraumatic Distress Inventory correlated with conceptually related measures, such as peritraumatic dissociation $(\mathrm{r}=0.59, \mathrm{p}<0.001)$, Civilian Mississippi Scale score $(\mathrm{r}=0.46, \mathrm{p}<0.001)$, and the intrusion $(\mathrm{r}=0.47, \mathrm{p}<0.001)$, avoidance $(\mathrm{r}=0.47, \mathrm{p}<0.001)$, and hyperarousal $(\mathrm{r}=0.42, \mathrm{p}<0.001)$ subscales of the Impact of Event Scale-Revised. These relationships persisted even after we partialled out the variance attributable to the SCL-90-R index of general psychopathology $(\mathrm{r}=0.24$ to $\mathrm{r}=0.53, \mathrm{p}<0.001)$ and the Peritraumatic Dissociative Experiences Questionnaire index of peritraumatic dissociation ( $\mathrm{r}=0.26$ to $\mathrm{r}=0.34, \mathrm{p}<0.001$ ).

The Peritraumatic Distress Inventory scores correlated modestly, or not at all, with conceptually different measures, such as social support $(\mathrm{r}=-0.11, \mathrm{p}<0.05)$, physical health $(r=-0.15, p<0.05)$, and time elapsed since the critical incident ( $r=-0.03, p>0.05)$. Examination of convergent and divergent validity was repeated in the comparison group with results similar to those found in the police officers.

\section{Discussion}

Many of the police officers and comparison subjects reported feelings of helplessness, sadness and grief, and frustration and anger; physical reactions such as sweating, shaking, and a racing heart; and being horrified after traumatic exposure. The occurrence and magnitude of such reactions was positively associated with two widely used measures of PTSD symptoms. These results echo the findings of other investigators $(8-12,14-16)$, most of whom, however, focused on a single type of peritraumatic distress response or did not control for general psychopathology or peritraumatic dissociation.

The Peritraumatic Distress Inventory was internally consistent and stable over time. Although most Peritraumatic Distress Inventory items had good to excellent correlations between item and total scores, a few, such as worry about the safety of others, did not. This finding is consistent with the notion that learning about another person's trauma, in contrast with directly witnessing it, often leads to PTSD. Difficulty controlling bowel and bladder and feeling like passing out were endorsed by fewer participants; these items also had lower item-total correlations, as was found in another study (13). It remains to be seen if such items are more frequently endorsed in other traumatized groups.

It is worthwhile to note that all of the main findings obtained in the group of police officers were replicated in the comparison subjects who were exposed to a variety of traumatic events. This increases confidence in the results and suggests that the Peritraumatic Distress Inventory is applicable to studies of trauma in the general population. 
We found moderate differences in responses related to gender and group membership. The women in the comparison group reported more peritraumatic distress than the female police officers, but the men in the comparison group did not differ from the male officers. More research will be needed to determine if female officers are more resilient to trauma than their civilian counterparts.

The most important limitations of the current study involve its cross-sectional design with retrospective report of peritraumatic distress. Recall may decay with time or be biased by current symptom levels (30). Another limitation relates to the requirement that participants complete the PTSD symptom scales in relation to a single event. The potential contribution of critical incidents other than the index event to current self-report of PTSD symptoms is an important and underexplored issue that is particularly salient in studies of highly exposed emergency services personnel.

Compared with peritraumatic dissociation, peritraumatic distress is an understudied phenomenon in the chain of events that may lead to the development of PTSD. The Peritraumatic Distress Inventory provides a tool to examine models of the genesis of PTSD, including the hypothesis that peritraumatic dysphoric arousal may enhance trauma-related memory and sensitize neurobiological systems implicated in the pathogenesis of PTSD.

Received June 26, 2000; revision received Jan. 19, 2001; accepted Feb. 22, 2001. From the Department of Psychiatry, University of California, San Francisco; the Department of Veterans Affairs Medical Center, San Francisco; and the Columbia School of Public Health, New York. Address reprint requests to Dr. Brunet, McGill University, Douglas Hospital Research Centre, 6875 LaSalle Blvd., Verdun, Quebec H4H 1R3, Canada; brunal@douglas.mcgill.ca (e-mail).

Supported by NIMH grant MH-56350 and by the Fonds de Recherche en Santé du Québec (Dr. Brunet).

\section{References}

1. Kessler RC, Sonnega A, Bromet E, Hughes M, Nelson CB: Posttraumatic stress disorder in the National Comorbidity Survey. Arch Gen Psychiatry 1995; 52:1048-1060

2. Marmar CR, Weiss DS, Metzler TJ: The Peritraumatic Dissociative Experiences Questionnaire, in Assessing Psychological Trauma and PTSD: A Handbook for Practitioners. Edited by Wilson JP, Keane TM. New York, Guilford, 1997, pp 412-428

3. Ozer EJ, Best SR, Lipsey TL, Weiss DS: Predictors of PTSD symptoms in adults: a meta-analysis, in Proceedings of the 1998 Meeting of the International Society for Traumatic Stress Studies. Northbrook, III, ISTSS, 1998, p 85

4. Koopman C, Classen C, Spiegel D: Predictors of posttraumatic stress symptoms among survivors of the Oakland/Berkeley, Calif, firestorm. Am J Psychiatry 1994; 151:888-894

5. Pitman RK: Post-traumatic stress disorder, hormones, and memory. Biol Psychiatry 1989; 26:221-223

6. Charney DS, Deutch AY, Krystal JH, Southwick SM, Davis M: Psychobiologic mechanisms of posttraumatic stress disorder. Arch Gen Psychiatry 1993; 50:295-305

7. March JS: What constitutes a stressor? the "criterion A" issue, in Posttraumatic Stress Disorder: DSM-IV and Beyond. Edited by
Davidson JRT, Foa EB. Washington, DC, American Psychiatric Press, 1993, pp 37-54

8. Bernat JA, Ronfeldt HM, Calhoun KS, Arias I: Prevalence of traumatic events and peritraumatic predictors of posttraumatic stress symptoms in a nonclinical sample of college students. J Trauma Stress 1998; 11:645-665

9. Brewin CR, Andrews B, Rose S: Fear, helplessness, and horror in posttraumatic stress disorder: investigating DSM-IV criterion A2 in victims of violent crime. J Trauma Stress 2000; 13:499-509

10. Roemer L, Orsillo SM, Borkovec TD, Litz BT: Emotional response at the time of a potentially traumatizing event and PTSD symptomatology: a preliminary retrospective analysis of the DSM-IV criterion A-2. J Behav Ther Exp Psychiatry 1998; 29:123-130

11. Solomon Z, Laor N, McFarlane AC: Acute posttraumatic reactions in soldiers and civilians, in Traumatic Stress: The Effects of Overwhelming Experience on Mind, Body, and Society. Edited by van der Kolk BA, McFarlane AC, Weisaeth L. New York, Guilford, 1996, pp 102-114

12. Ehlers A, Mayou RA, Bryant B: Psychological predictors of chronic posttraumatic stress disorder after motor vehicle accidents. J Abnorm Psychol 1998; 107:508-519

13. Lehman $\mathrm{H}$ : Somatic and psychological symptoms after the experience of life threatening events: a profile analysis. Victimology $1985 ; 10: 512-538$

14. Tucker P, Dickson W, Pfefferbaum B, McDonald NB, Allen G: Traumatic reactions as predictors of posttraumatic stress six months after the Oklahoma City bombing. Psychiatr Serv 1997; 48:1191-1194

15. Shalev AY, Sahar T, Freedman S, Peri T, Glick N, Brandes D, Orr SP, Pitman RC: A prospective study of heart rate response following trauma and the subsequent development of posttraumatic stress disorder. Arch Gen Psychiatry 1998; 55:553-559

16. Resnick HS: Acute panic reactions among rape victims: implications for prevention of postrape psychopathology. National Center for PTSD Clinical Quarterly 1997; 7:41-45

17. Weiss DS, Brunet A, Metzler TJ, Best SR, Fagan JA, Marmar CR: Critical incident exposure in police officers: frequency, impact, and correlates, in Proceedings of the 1999 Meeting of the International Society for Traumatic Stress Studies. Northbrook, III, ISTSS, 1999, p 52

18. Green BL: Psychometric review of the Trauma History Questionnaire, in Measurement of Stress, Trauma, and Adaptation. Edited by Stamm BH. Lutherville, Md, Sidran, 1996, pp 366-369

19. Corcoran CB, Green BL, Goodman LA, Krinsley KE: Conceptual and methodological issues in trauma history assessment, in International Handbook of Human Response to Trauma. Edited by Shalev AY, Yehuda R, McFarlane AC. New York, Plenum, 2000, pp 223-232

20. Weiss DS, Marmar CR: The Impact of Event Scale-Revised, in Assessing Psychological Trauma and PTSD: A Practitioner's Handbook. Edited by Wilson JP, Keane TM. New York, Guilford, 1997, pp 399-411

21. Vreven DL, Gudanowski DM, King LA, King DW: The civilian version of the Mississippi PTSD Scale: a psychometric evaluation. J Trauma Stress 1995; 8:91-109

22. Derogatis LR: SCL-90-R: Administration, Scoring, and Procedures Manual, 3rd ed. Towson, Md, Clinical Psychometric Research, 1994

23. Kulka RA, Schlenger WE, Fairbank JA, Hough RL, Jordan BK, Marmar CR, Weiss DS: Trauma and the Vietnam War Generation: Report of Findings From the National Vietnam Veterans Readjustment Study. New York, Brunner/Mazel, 1990

24. Reynolds WM: Development of reliable and valid short forms of the Marlowe-Crowne Social Desirability Scale. J Clin Psychol 1982; 38:119-125 
25. Ware JE, Kosinski M, Keller SD: A 12-item Short-Form Health Survey-construction of scales and preliminary tests of reliability and validity. Med Care 1996; 34:220-233

26. Benjamini $Y$, Hochberg $Y$ : Controlling the false discovery rate-a practical and powerful approach to multiple testing. J Royal Statistical Society Series B: Methodological 1995; 57: 289-300

27. Dempster AP, Laird NM, Rubin DB: Maximum likelihood from incomplete data via the EM algorithm. J Royal Statistical Society B: Methodological 1977; 39:1-38
28. Marmar CR, Weiss DS, Metzler TJ, Ronfeldt HM, Foreman C: Stress responses of emergency services personnel to the Loma Prieta earthquake interstate 880 freeway collapse and control traumatic incidents. J Trauma Stress 1996; 9:63-85

29. Brunet A, Weiss D, Metzler T, Best S, Fagan J, Vedantham K, Marmar CR: An overview of the Peritraumatic Emotional Distress Scale. Dialogues in Clin Neurosci 2000; 2:44-45

30. Southwick SM, Morgan CA III, Nicolaou AL, Charney DS: Consistency of memory for combat-related traumatic events in veterans of Operation Desert Storm. Am J Psychiatry 1997; 154: 173-177 